\title{
Acute exercise enhances the consolidation of fear extinction memory and reduces conditioned fear relapse in a sex-dependent manner
}

\author{
Courtney A. Bouchet, ${ }^{1}$ Brian A. Lloyd, ${ }^{1}$ Esteban C. Loetz, ${ }^{1}$ Caroline E. Farmer, ${ }^{1}$ \\ Mykola Ostrovskyy, ${ }^{1}$ Natalie Haddad, ${ }^{1}$ Rebecca M. Foright, ${ }^{2}$ and Benjamin \\ N. Greenwood ${ }^{1}$ \\ ${ }^{1}$ Department of Psychology, University of Colorado Denver, Denver, Colorado 80217, USA; ${ }^{2}$ Division of Endocrinology, Metabolism, and \\ Diabetes, Department of Medicine, University of Colorado Anschutz Medical Campus, Aurora, Colorado 80045, USA
}

Fear extinction-based exposure therapy is the most common behavioral therapy for anxiety and trauma-related disorders, but fear extinction memories are labile and fear tends to return even after successful extinction. The relapse of fear contributes to the poor long-term efficacy of exposure therapy. A single session of voluntary exercise can enhance the acquisition and consolidation of fear extinction in male rats, but the effects of exercise on relapse of fear after extinction are not well understood. Here, we characterized the effects of $2 \mathrm{~h}$ of voluntary exercise during the consolidation phase of contextual or auditory fear extinction learning on long-term fear extinction memory and renewal in adult, male and female, LongEvans rats. Results indicate that exercise enhances consolidation of fear extinction memory and reduces fear relapse after extinction in a sex-dependent manner. These data suggest that brief bouts of exercise could be used as an augmentation strategy for exposure therapy, even in previously sedentary subjects. Fear memories of discrete cues, rather than of contextual ones, may be most susceptible to exercise-augmented extinction, especially in males. Additionally, exercise seems to have the biggest impact on fear relapse phenomena, even if fear extinction memories themselves are only minimally enhanced.

Fear conditioning is an associative learning phenomenon during which a previously innocuous cue (conditioned stimulus; CS) comes to elicit an emotional fear response because of its association with an aversive stimulus (unconditioned stimulus; US). Mechanisms underlying fear conditioning are thought to go awry in anxiety and trauma-related disorders (Elzinga and Bremner 2002). Fear extinction, the decay of a fear response to a CS following repeated presentation of the fear-evoking CS in the absence of the aversive US (Pavlov 1927), forms the basis of exposure therapy, the behavioral therapy of choice for anxiety and trauma-related disorders. Unfortunately, extinction memories are labile and susceptible to relapse phenomena such as renewal (Bouton 1988), spontaneous recovery (Pavlov 1927), and reinstatement (Rescorla and Heth 1975); which together contribute to the poor long-term efficacy of exposure therapy (Boschen et al. 2009; Neumann and Kitlertsirivatana 2010). Identification of novel means to render fear extinction memories impervious to relapse is of utmost importance to mental health. One factor that enhances many learning and memory processes and could potentially modulate fear extinction is physical activity.

Despite the well-established benefits of chronic exercise on cognition and learning processes (Cotman and Berchtold 2002; Hillman et al. 2003, 2014; Cassilhas et al. 2015; Prakash et al. 2015), the lingering changes in the brain produced by habitual exercise are not sufficient to enhance fear extinction (Greenwood et al. 2009). Moreover, maintenance of chronic exercise is essential for use in a clinical setting, yet maintaining regular exercise is a constant challenge and long-term exercise adherence rates are

\section{Corresponding author: benjamin.greenwood@ucdenver.edu}

Article is online at http://www.learnmem.org/cgi/doi/10.1101/lm.045195. 117. low (Dishman 1982; Hogg et al. 2012; Zuckoff 2012) even when initial motivation is high (Van Roie et al. 2015). In contrast to weeks of repeated exercise, individuals may be more likely to adhere to a recommendation of a relatively few sessions of exercise. A few acute bouts of exercise could be more practical to implement in clinical settings than repeated exercise. Even so, prior research investigating the effects of a single, recent bout of exercise (acute exercise) as a treatment for anxiety or trauma-related disorders is limited. Investigating the effects of acute exercise within the context of fear extinction learning and memory in an animal model is an initial step toward utilization of acute exercise in a clinical setting.

Fear extinction learning incorporates two critical phases: the acquisition phase and the consolidation phase. During the acquisition phase, the association between the fear-eliciting CS and the lack of the predicted aversive event is initially encoded. Later, during the consolidation phase, molecular processes take place in the neural circuits responsible for forming the long-term memory of fear extinction. Previous research investigating the effects of chronic exercise on subsequent contextual (Greenwood et al. 2009) or auditory (Dubreucq et al. 2015) fear extinction report negative results, possibly due to the inability of prior chronic exercise to target a distinct extinction learning phase. Exercise initiates a plethora of physiological and neurobiological events; the timing of which in relation to a specific phase of fear extinction learning

\footnotetext{
C) 2017 Bouchet et al. This article is distributed exclusively by Cold Spring Harbor Laboratory Press for the first 12 months after the full-issue publication date (see http://learnmem.cshlp.org/site/misc/terms.xhtml). After 12 months, it is available under a Creative Commons License (AttributionNonCommercial 4.0 International), as described at http://creativecommons. org/licenses/by-nc/4.0/.
} 
could be critical for the ability of exercise to modulate fear extinction.

There is evidence that acute exercise, within a small temporal window in relation to fear extinction learning, can modulate later fear extinction memory and relapse. Siette et al. (2014) reported that previously sedentary male rats allowed $3 \mathrm{~h}$ of voluntary exercise either immediately before or after contextual fear extinction displayed improved retention of fear extinction memory when tested the next day. However, if rats were allowed the same $3 \mathrm{~h}$ of acute exercise $6 \mathrm{~h}$ after fear extinction, presumably after the consolidation phase, exercise had no effect on extinction memory retention (Siette et al. 2014). A pilot study in humans revealed a similar effect. Powers et al. (2015) allowed mostly female patients suffering from post-traumatic stress disorder (PTSD) to engage in moderate intensity treadmill exercise for $30 \mathrm{~min}$ immediately prior to each of 12 sessions of exposure therapy. Those patients who exercised prior to exposure therapy showed significant improvement of PTSD symptoms immediately following the final therapeutic session, relative to patients who had 90 min of exposure therapy without exercise. Further, Mika et al. (2015) found that male rats allowed to run in wheels during the acquisition of auditory fear extinction, relative to rats extinguished in locked wheels, demonstrated reduced fear when reexposed to the CS 1 wk later in a novel context.

Although prior data suggest that acute exercise can enhance the acquisition or consolidation of fear extinction in such a way as to reduce fear relapse, critical questions remain unanswered. Siette et al. (2014) did not investigate the effects of acute exercise on relapse of contextual fear conditioning following extinction, and the experimental design used in Mika et al. (2015) did not allow the differentiation of the effects of acute exercise on auditory fear extinction memory from its relapse. Further, none of these previous experiments have investigated the effects of voluntary wheel running on fear extinction learning, memory, and relapse in female rats. This is a critical oversight, as females can have impaired fear extinction depending on their estrus cycle phase (Milad et al. 2009) and, relative to males, have a higher incidence of anxiety (McLean et al. 2011) and are more likely to develop PTSD (Breslau et al. 1997). The goal of the current studies was to further characterize effects of acute, voluntary exercise on consolidation and relapse of contextual and auditory conditioned fear in both males and cycling females. It is hypothesized that acute exercise during the consolidation phase of fear extinction learning will enhance fear extinction memory and reduce later fear relapse in both sexes.

\section{Results}

\section{Experiment 1: exercise during consolidation of contextual fear extinction improves long-term memory of fear extinction in males}

A timeline for the Experiment is shown in Figure 1A. Rats used in experiment 1 ran equal amounts during the running familiarization period regardless of subsequent exposure to fear extinction (Fig. 2A). Rats exhibited low levels of freezing prior to the first US during contextual fear conditioning (pre; Fig. 3A). Freezing levels increased throughout US presentations $\left(F_{(2,56)}=62.25, P<0.0001\right)$ and did not differ between rats subsequently assigned to immobile wheels (Locked) or freely mobile (Mobile) conditions, nor between No Extinction $(N=10)$ and Extinction $(N=22$; Fig. $3 A)$. There was an indication of a trend toward a positive correlation between average distance run during the wheel running familiarization period and freezing during fear conditioning $(R=0.299$, $F_{(1,29)}=2.86 ; P=0.1$; Fig. $\left.6 \mathrm{~A}\right)$; an observation that would be consistent with prior reports indicating that wheel running enhances contextual fear conditioning (Van Hoomissen et al. 2004; Burghardt et al. 2006; Greenwood et al. 2009; Kohman et al. 2012).

Freezing levels during the first fear extinction training session did not differ between rats subsequently placed into Locked or Mobile wheels (Fig. 3B), and distance run during the running familiarization period did not predict the amount of freezing during the first extinction training session. Running distances during the $2 \mathrm{~h}$ following the first and subsequent fear extinction training sessions are shown in Figure 2B. Exercise immediately following contextual fear extinction training had no effect on fear extinction memory. Rats in Locked and Mobile conditions displayed similar levels of freezing and within-session extinction (not shown) during the second (Fig. 3C) and third (Fig. 3D) fear extinction training sessions, which also served as fear extinction memory tests. Distance run during the consolidation of the first and second contextual fear extinction sessions was; however, negatively correlated to freezing levels during the second and third fear extinction memory tests $\left(R=0.60 ; F_{(1,9)}=5.07, P=0.05\right.$; Fig. $\left.6 \mathrm{C}\right)$.

Rats were again reexposed to Context A 1 wk after the third fear extinction training session in order to determine whether post-extinction wheel running facilitated long-term memory of contextual fear extinction. Because freezing levels a week after fear extinction training are modulated both by the strength of the extinction memory and the spontaneous recovery of fear (Bouton 1993; Ponnusamy et al. 2016), this memory test at Day 10 represented both a long-term extinction memory test and a test of spontaneous recovery. However, freezing levels displayed by all rats exposed to fear extinction training remained at low levels during the extinction memory test at Day 10 (Fig. 3E), indicating minimal spontaneous recovery. The lack of spontaneous recovery could be due to rats receiving three sessions of fear extinction training, thus producing a strong fear extinction memory. Despite this, rats that ran after fear extinction displayed significantly less fear during the long-term extinction memory test than rats placed into locked wheels after fear extinction $(P<0.05)$; further, this effect of exercise was dependent on exercise being contingent with fear extinction (interaction between Exercise and Extinction: $F_{(1,28)}=6.47, P=0.01$; Fig. $3 \mathrm{E}$ ). Rats that ran similar amounts (Fig. 2) but were not exposed to fear extinction (Mobile-No Ext), displayed levels of freezing greater than that expressed by rats exposed to extinction $(P<0.05)$, and no different from Locked rats not exposed to fear extinction (Locked-No Ext; Fig. 3E). These data indicate that exercise during the consolidation of contextual fear extinction facilitates retrieval of fear extinction memory at longterm time points.

\section{Experiment 2: exercise during consolidation of auditory fear extinction improves fear extinction memory and reduces fear renewal in males}

Rats exhibited low levels of freezing prior to the first CS-US pairing (pre; Fig. 4A). Freezing levels increased throughout conditioning $\left(F_{(3,111)}=58.20, P<0.0001\right)$ and did not differ between rats subsequently assigned to Locked or Mobile conditions. Rats in Experiment 2 ran distances similar to rats in Experiment 1 during the running familiarization period (Fig. 2A). Interestingly, the average running distance during the wheel running familiarization period negatively correlated with freezing levels during fear conditioning $\left(R=-0.48 ; F_{(1,36)}=10.699 ; P<0.01 ;\right.$ Fig. $\left.6 \mathrm{~A}\right)$. These data suggest that unlike chronic wheel running which has been reported to have no effect on the acquisition of auditory fear conditioning (Baruch et al. 2004), brief access to running wheels could interfere with auditory fear conditioning learning. One wheel did not record running distance during the wheel running familiarization period, so this rat was omitted from this correlational analysis. 


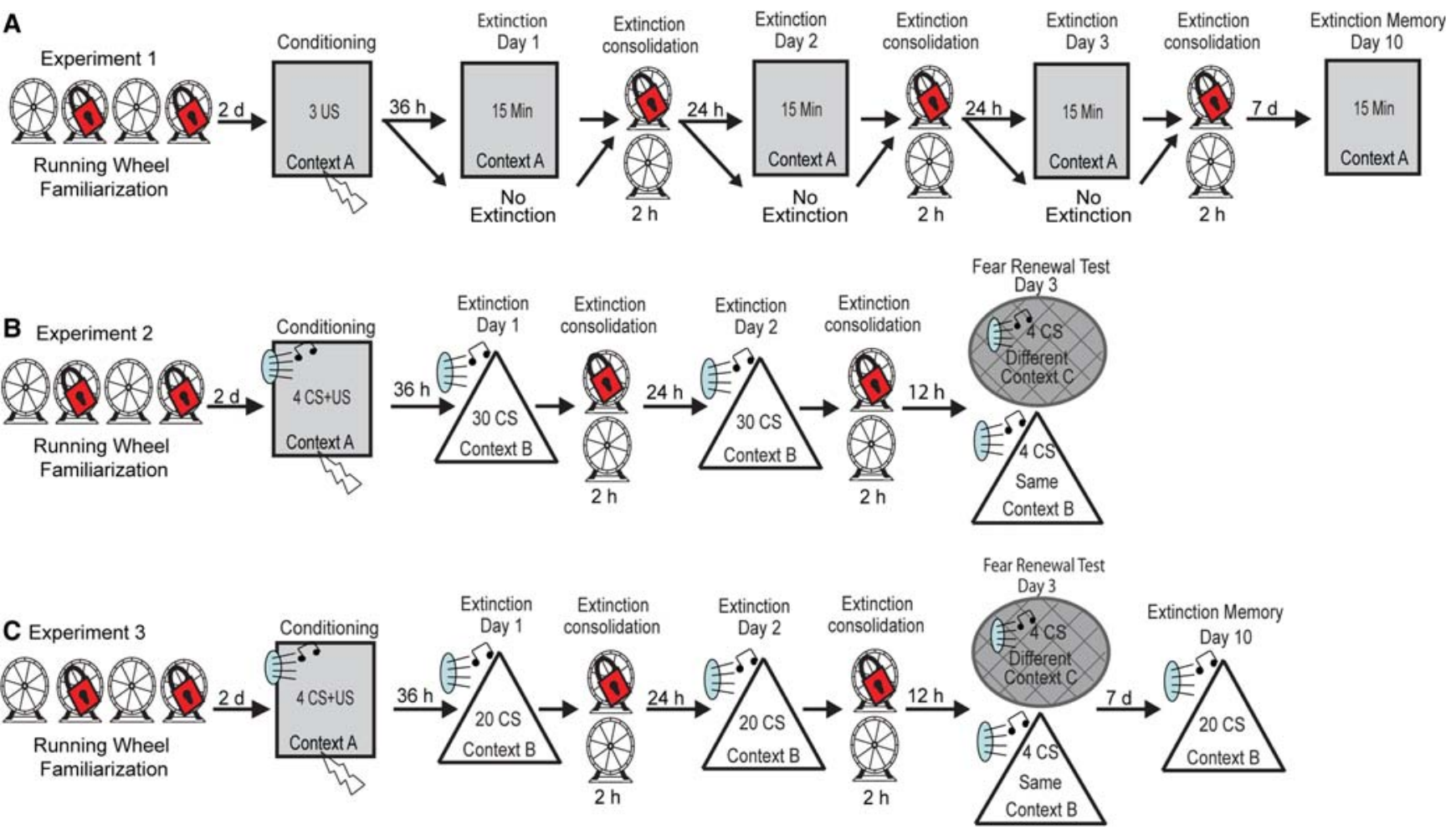

Figure 1. Experimental design. (A) All rats were placed into unlocked and locked wheels on alternating nights for four nights to equally familiarize rats with mobile and locked running wheels. Three days following the last running opportunity, rats were exposed to contextual fear conditioning in Context A by administering an unsignaled 1-sec, $0.8-\mathrm{mA}$ footshock unconditioned stimulus (US) three times with a 1- min inter-trial interval (ITI). The following evening, all rats were placed back into the familiar conditioning Context A for 15 min immediately followed by $2 \mathrm{~h}$ in either locked or mobile running wheels. Contextual fear extinction followed by $2 \mathrm{~h}$ in locked or mobile wheels was repeated the following two evenings. One week following the last extinction trial, rats were placed into the conditioning Context A to assess long-term fear extinction memory. (B) All rats were placed into mobile and locked wheels on alternating nights for four nights to equally familiarize rats with mobile and locked running wheels. Three days following the last running opportunity, rats were conditioned to fear a tone in Context A by coterminating a $10 \mathrm{sec}, 80 \mathrm{~dB}$ tone conditioned stimulus (CS) with a 1-sec, 0.8-mA footshock US four times with a 1-min ITI. The following evening, all rats were placed into a novel extinction Context B and exposed to the auditory CS 30 times in the absence of the footshock US (1-min ITI). Immediately following fear extinction, rats were placed into either mobile or locked running wheels for 2 h. The fear extinction and running procedure was repeated the following evening, for a total of two nights of fear extinction following by either mobile or locked conditions. The morning after the second fear extinction trial, half of the rats were placed into the familiar, extinction Context $B$ and the other half were placed into a novel Context $C$ to test for fear renewal. (C). Experiment 2 was repeated with female rats with extinction consisting of 20 CS presentations instead of the $30 \mathrm{CS}$ presentations as in experiment 2. One week following the fear renewal test, rats were placed back into Context B to assess long-term fear extinction memory.

All rats exhibited negligible amounts of freezing prior to the first CS during Day 1 of auditory fear extinction training in Context $\mathrm{B}$, indicating that minimal fear transferred from the conditioning Context A to the fear extinction Context B (not shown). Freezing levels decreased across trials $\left(F_{(5,185)}=147.12, P<0.0001\right)$ and did not differ between rats subsequently placed into Locked or Mobile wheels (Fig. 4B). The average running distance during the familiarization period negatively correlated with freezing levels during the first four trials of the first fear extinction training session $\left(R=-0.34 ; F_{(1,36)}=4.60 ; P<0.05 ;\right.$ Fig. 6B), consistent with the negative relationship between running distance and the initial acquisition of auditory fear conditioning (Fig. 6A).

Running distances during the $2 \mathrm{~h}$ following the auditory fear extinction training sessions are shown in Figure 2B. Post-extinction wheel running facilitated fear extinction memory. When reexposed to the extinction Context B the evening following post-fear extinction running, Mobile rats displayed significantly less freezing than locked rats across the duration of the fear extinction training session, which also served as a fear extinction memory test $\left(F_{(1,37)}=6.10, P=0.01\right.$; Fig. $\left.4 \mathrm{C}\right)$. Locked and Mobile rats displayed equivalent within-session extinction, as freezing levels decreased over time in both groups $\left(F_{(5,185)}=43.67 ; P<0.0001\right.$; Fig. $\left.4 \mathrm{C}\right)$.
Distance run after the first auditory fear extinction training session did not predict levels of freezing during the second fear extinction training session.
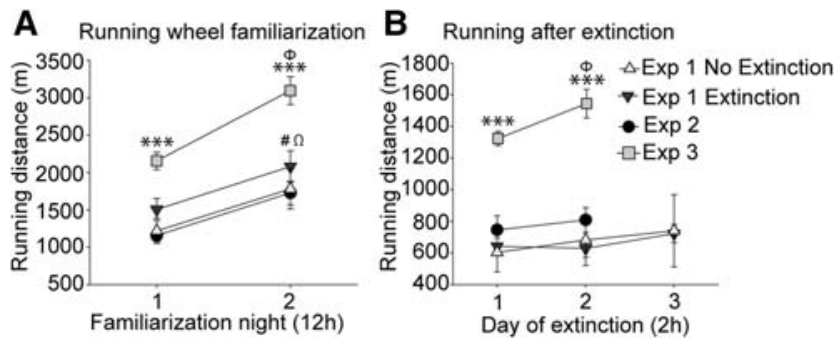

Figure 2. Running distances. Female rats in experiment 3 (Exp. 3) ran more than male rats used in experiment 1 (Exp. 1) and experiment 2 (Exp. 2), both $(A)$ during the running familiarization phase and $(B)$ during the $2 \mathrm{~h}$ running bouts after fear extinction training. Data displayed represent mean \pm SEM. Exp. 3 different from all other groups $\left(^{* * *}\right) P<$ 0.0001 ; Exp. 3 Day 2 different from Exp. 3 Day $1(\Phi) P<0.01$; Exp. 2 Day 2 different from Exp. 2 Day 1 (\#) $P<0.01$; Exp. 1 Extinction Day 2 different from Exp. 1 Extinction Day $1(\Omega) P<0.01$. 


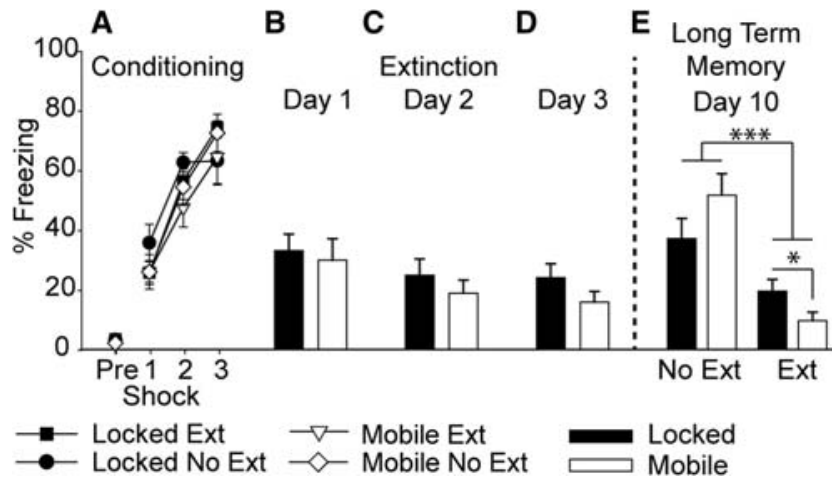

Figure 3. Running after contextual fear extinction, but not running alone, enhances long-term extinction memory. (A) Freezing levels increased throughout US presentations during contextual fear conditioning (three, 1-sec, 0.8-mA footshocks, 1-min ITI), regardless of subsequent group assignments. $(B)$ There was no significant difference in freezing during the first fear extinction training session $1 \mathrm{~d}$ after conditioning between rats subsequently placed in either locked (Locked) or mobile (Mobile) running wheels. $(C, D)$ Wheel running during the consolidation of contextual fear extinction had no impact on fear extinction memory during memory tests on Days 2 and 3. (E) Rats that ran after extinction exhibited significantly less fear than those placed into locked wheels after extinction. Both Locked and Mobile rats that went through fear extinction (Ext) froze significantly less than those that were not exposed to fear extinction (No Ext). Data displayed represent mean \pm SEM; $\left({ }^{*}\right) P<0.01$. $\left.{ }^{* * *}\right) P<0.0001$.

Rats were again placed into their locked or mobile wheels for 2 $\mathrm{h}$ following the second fear extinction training session. Then, to determine the effect of wheel running during consolidation of auditory fear extinction on renewal of auditory conditioned fear, rats were reexposed to the extinguished CS in either Context B (Same) or a novel Context C (Different) the following day. Locked rats displayed typical fear renewal, as Locked rats reexposed to the extinguished CS in a context different from where fear extinction was learned exhibited more fear than Locked rats reexposed to the CS in the same extinction context $(P<0.05)$. Rats allowed to exercise during the consolidation of auditory fear extinction; however, were protected from fear renewal (interaction between Exercise and Context: $\left.F_{(1,35)}=5.11, \quad P<0.05\right)$. Distance run after the second fear extinction training session did not predict the levels of freezing in either context during the renewal test on Day 3.

\section{Experiment 3: exercise during consolidation of auditory fear extinction fails to improve fear extinction memory or reduce fear renewal in females}

Analyses of the freezing data during the renewal test on Day 3 was consistent with prior work (Lebron-Milad and Milad 2012) suggesting that estrus phase during fear extinction learning modulates later retrieval of fear extinction. Specifically, levels of freezing expressed during the renewal test by rats that were in metestrus and diestrus (Met\&Di; $n=$ 17) during initial fear extinction learning on Extinction Day 1 differed from rats that were in proestrus and estrus (Pro\&E; $n=23$ ) on Extinction Day 1. In contrast, estrus phase during conditioning or renewal had no impact on freezing levels during any behavioral test. Therefore, females were separated into groups according to phase of the estrus cycle on the first day of fear extinction training (Extinction Day 1). Photomicrographs of vaginal cytology defining the estrus phases are shown in Figure 5F-I.

Overall distance run on the second wheel running familiarization day increased significantly from the first wheel familiarization opportunity (main effect of time: $F_{(1,105)}=54.297 ; P<0.0001$ ), with female rats running significantly further than male rats (main effect of experiment: $F_{(3,105)}=17.456 ; P<0.0001$; Fig. $2 \mathrm{~A}$ ). Unlike the males, the distance run during the wheel running familiarization period did not predict levels of freezing during fear conditioning in female rats. Rats exhibited low levels of fear prior to the first CS-US pairing during conditioning (pre; Fig. 5A). Freezing levels increased throughout CS-US pairings $\left(F_{(3,108)}=\right.$ $45.63, P<0.0001$; Fig. 5A) for all rats regardless of subsequent estrus cycle phase or subsequent wheel assignment.

Freezing levels in all groups were negligible prior to the first CS during Day 1 of auditory fear extinction training in Context B (data not shown). Freezing levels decreased across trials $\left(F_{(4,144)}=76.28\right.$, $P<0.0001$; Fig. 5B) and did not differ between estrus phases or between rats subsequently placed into Locked or Mobile wheels. The average running distance during wheel familiarization did not predict levels of freezing during the first fear extinction training session.

Rats were placed into either locked or mobile wheels immediately following fear extinction. Post-fear extinction running distances did not differ between rats at different stages of the estrus cycle, so running distances were averaged across all females (Fig. 2B). Female rats ran significantly more than male rats during the $2 \mathrm{~h}$ running opportunities following fear extinction $\left(F_{(3,48)}=\right.$ 29.09; $P<0.0001)$. Additionally, female rats' running distance escalated across nights $(P<0.05)$, whereas the males maintained running distances across subsequent post-extinction running opportunities (Fig. 2B). Despite the greater distances run by females,

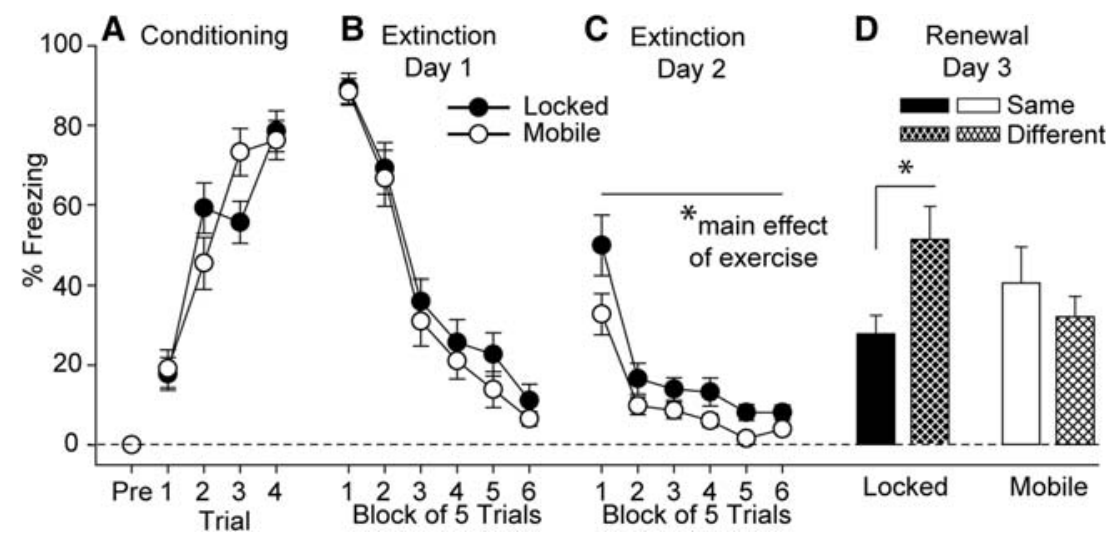

Figure 4. Exercise enhances auditory fear extinction memory and blocks renewal in males. $(A)$ Fear increased throughout conditioning trials (four pairings of 10-sec, 80-dB, 2-kHz auditory CS coterminating with 1-sec, 0.8-mA footshock US) and was not different between rats subsequently assigned to locked (Locked) or mobile (Mobile) wheel conditions. (B) Rats were placed into a novel extinction context and exposed to 30 CS presentations (1-min ITI) in the absence of the US. Freezing decreased throughout the extinction trials and did not differ between rats subsequently assigned to locked or mobile conditions. (C) When reexposed to the CS in the extinction context, rats in the Mobile group displayed significantly less fear behavior than those in the Locked group. $(D)$ Locked rats placed into a context different from that in which extinction was learned (Different) displayed typical fear renewal. Rats placed into Mobile wheels after fear extinction were protected from fear renewal. Data displayed represent mean \pm SEM; $\left(^{*}\right) P<0.01$. 


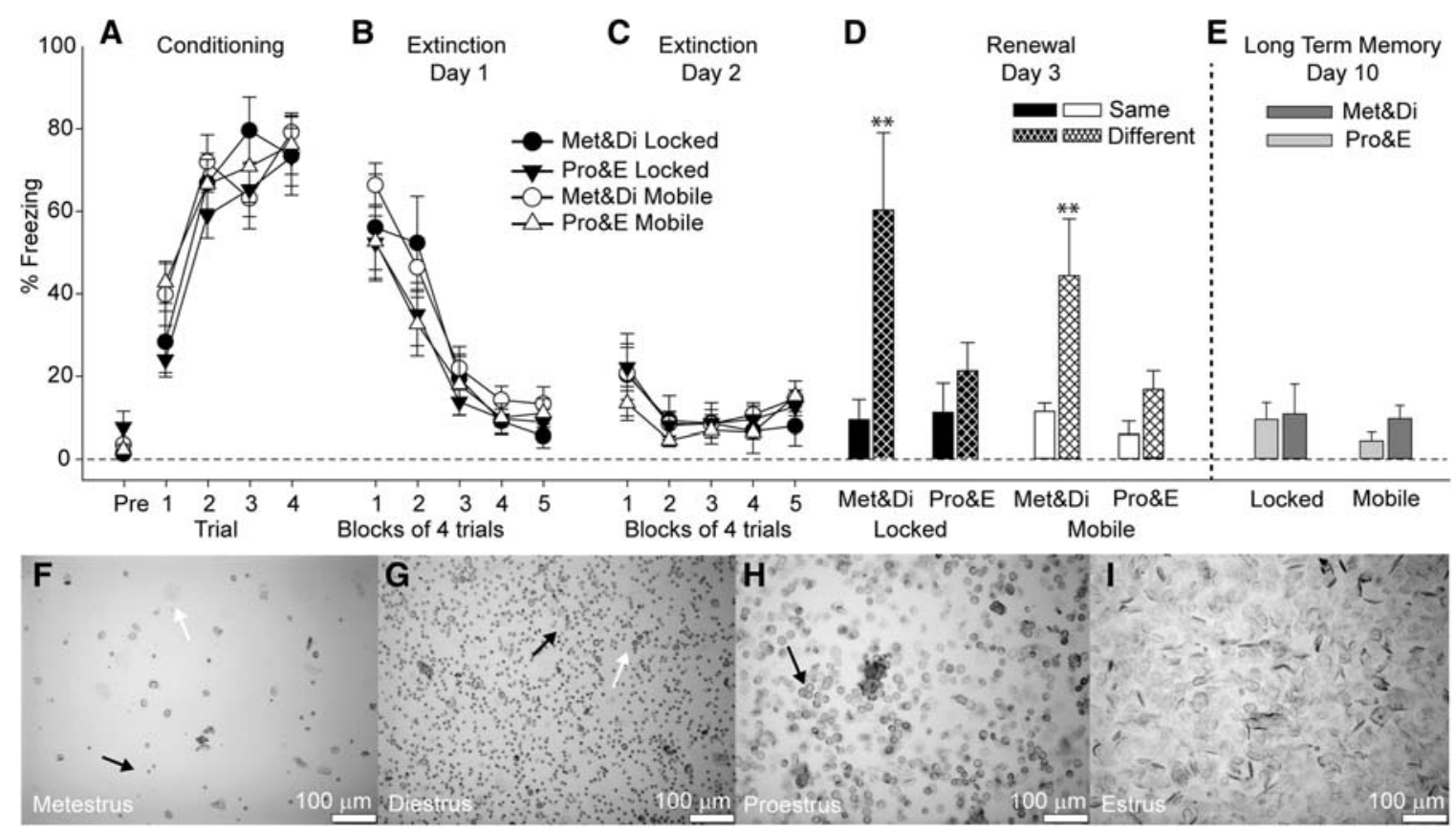

Figure 5. Phase of estrus cycle, but not exercise, modulates fear renewal in female rats. Rats were grouped by phase of estrus cycle during fear extinction learning (fear Extinction Day 1). (A) Fear increased throughout conditioning trials (four pairings of 10-sec, 80-dB, 2-kHz auditory CS coterminating with 1 -sec, 0.8-mA footshock US), and was not different between rats subsequently assigned to locked (Locked) or mobile (Mobile) wheel conditions. (B) Rats were placed into a novel extinction context and exposed to $20 \mathrm{CS}$ presentations (1-min ITI) in the absence of the US. Freezing decreased throughout the extinction trials and did not differ between rats in metestrus and diestrus (Met\&Di) or proestrus and estrus (Pro\&E) phases of the estrus cycle, or subsequently assigned to Locked or Mobile conditions. (C) Freezing levels were similar between all groups and all rats demonstrated similar within-session extinction regardless of estrus phase or exercise condition. $(D)$ Rats that were in Met\&Di during fear Extinction Day 1 displayed typical fear renewal when reexposed to the CS in a context different from where extinction was learned (Different). Rats that were in Pro\&E during fear Extinction Day 1 were protected against the renewal of fear. $(E)$ No differences between groups were observed when rats were reexposed to the CS in Context B 1 wk after the fear renewal test. $(F)$ Photomicrograph of vaginal cytology showing keratinized epithelial cells (white arrow) and leukocytes (black arrow) characteristic of metestrus. (G) Photomicrograph of vaginal cytology showing predominately leukocytes (white arrow) and nucleated epithelial cells (black arrow) with a decrease in anucleated keratinized epithelial cells. $(H)$ Photomicrograph of vaginal cytology showing small, round, often clumped mononucleated cells (arrow) of relatively the same size. (I) Photomicrograph of vaginal cytology showing predominately anucleated keratinized epithelial cells. Data displayed represent mean \pm SEM; $\left.{ }^{* *}\right) P<0.001$.

post-extinction wheel running did not facilitate auditory fear extinction memory in females. When reexposed to the auditory CS in the extinction Context $\mathrm{B}$ the evening following post-fear extinction running, freezing levels were similar between groups and all rats demonstrated similar within-session extinction $\left(F_{(4,144)}=\right.$ 8.91, $P<0.0001$; Fig. 5C). Freezing within the first few trials of the second fear extinction training session is considered extinction memory retrieval (Bukalo et al. 2015; Do-Monte et al. 2015). Thus, to verify that post-extinction running did not impact fear extinction memory, freezing during the first four trials of Extinction Day 2 was analyzed separately. No differences between groups were observed during the first four trials (data not shown). Distance run after the first auditory fear extinction training session did not predict levels of freezing during the second fear extinction training session.

Rats in the Mobile group were again allowed to run for $2 \mathrm{~h}$ following the second fear extinction training session. Then, to determine the effect of wheel running during consolidation of auditory fear extinction on renewal of auditory conditioned fear, rats were reexposed to the extinguished CS in either Context B (Same) or a novel Context C (Different) the following day. Results are shown in Figure 5D. Rats placed into the Different context the next day displayed more freezing behavior than rats placed into the Same context $\left(F_{(1,32)}=14.40, P<0.001\right)$, indicating renewal of fear in the Different context. Rats in the Met\&Di group displayed significantly higher freezing levels compared with Pro\&E rats $\left(F_{(1,32)}=\right.$ $6.54, P=0.01)$, regardless of context. Moreover, ANOVA revealed an interaction between context and estrus phase $\left(F_{(1,32)}=5.22, P\right.$ $<0.05)$, indicating that rats in the Met\&Di group displayed significantly more fear renewal than rats in the Pro\&E group. Unlike males, wheel running during the consolidation of auditory fear extinction had no effect on freezing levels during the renewal test in females. Interestingly; though, the average running distance after both extinction training sessions negatively correlated with freezing levels in the Same context, but this association just missed significance $\left(R=-0.58, F_{(1,8)}=4.14, P=0.07\right.$; Fig. $\left.6 \mathrm{D}\right)$. No other significant correlations between freezing and running distance were found.

Rats were again reexposed to Context B 1 wk after the fear renewal test to determine if post-extinction wheel running facilitated long-term memory of auditory fear extinction. Neither context on Day 3 of testing (Same vs. Different), phase of estrus cycle during Day 1 of fear extinction training (Met\&Di vs. Pro\&E), nor wheel running (Locked vs. Mobile) impacted freezing levels when reexposed to the CS 1 wk later (Fig. 5E).

\section{Discussion}

Here we report the novel findings that a brief increase in physical activity during the consolidation phase of fear extinction learning can enhance fear extinction and render fear extinction memory resistant to relapse. In males, wheel running during consolidation of contextual fear extinction improved long-term memory of fear 
A
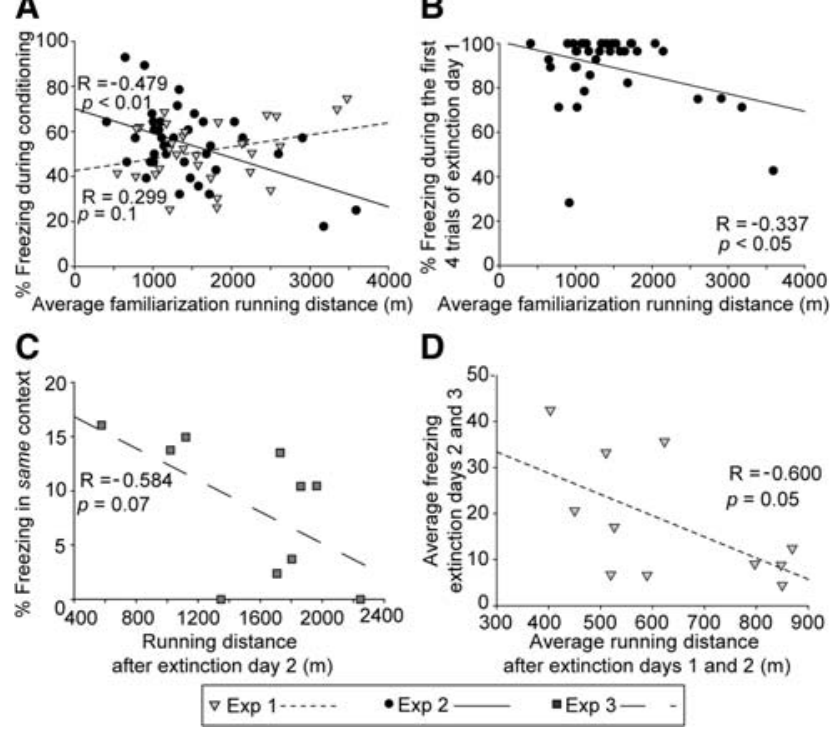

Figure 6. Correlations between running and freezing levels. (A) Average running distance during running familiarization did not predict freezing during contextual fear conditioning in experiment 1 (Exp. 1), but negatively correlated with freezing during auditory fear conditioning in experiment 2 (Exp. 2). (B) The average running distance during running familiarization negatively correlated with freezing during the first four tones of fear Extinction Day 1 in Exp. 2. (C) There was a trend for the average running distance following the auditory fear extinction sessions to negatively correlate with freezing in the Same context during the fear renewal test in females in experiment 3 (Exp. 3). (D) Average running distance after the first and second fear extinction training sessions negatively correlated with average freezing levels during the second and third fear extinction training sessions (Exp. 1).

extinction, recall of which is influenced by spontaneous recovery. Similarly, wheel running during the consolidation of auditory fear extinction improved fear extinction memory and prevented the renewal of fear. In both cases, rats that ran the greatest distance during the consolidation phase of fear extinction learning also tended to have the strongest extinction memory. Exercise, however, only improved fear extinction in males. In females, wheel running had no impact on either fear extinction consolidation or renewal of fear. However, females that ran the greatest distance during auditory fear extinction consolidation did tend to have the strongest fear extinction memory. Interestingly, females that learned fear extinction during proestrus and estrus phases of the estrus cycle were protected against fear renewal. Along with prior data (Siette et al. 2014; Mika et al. 2015; Powers et al. 2015), these results suggest that brief exercise bouts could be used as an augmentation strategy for exposure therapy, even in previously sedentary subjects. Fear memories of discrete cues, rather than of contextual ones, may be most susceptible to exercise-augmented extinction, especially in males. Moreover, exercise seems to have the biggest impact on fear relapse phenomena, even if fear extinction memories themselves are only minimally enhanced, as is the case with contextual fear extinction. Further research is warranted to determine the effectiveness of exercise-augmentation of fear extinction in a clinical setting.

In experiment 1 , post-extinction exercise only enhanced consolidation of contextual fear extinction when memory was assessed 1 wk after the final extinction training session. This observation differs from that of Siette et al. (2014), who observed that Wistar rats allowed to run during consolidation of contextual fear extinction had improved recall of fear extinction the next day. One difference between our experiment and the Siette et al. (2014) study is that rats in the current experiment had access to running wheels for two active cycles prior to fear conditioning, whereas the rats in the Siette et al. (2014) study were naïve to running wheels. This prior brief access to running wheels may have made the contextual fear memory more difficult to extinguish. Indeed, only $2 \mathrm{~d}$ of wheel running increases BDNF mRNA in the hippocampus (Neeper et al. 1995, 1996) and it is well established that wheel running prior to conditioning enhances contextual fear conditioning (Van Hoomissen et al. 2004; Burghardt et al. 2006; Greenwood et al. 2009; Kohman et al. 2012) and makes it more difficult to extinguish (Greenwood et al. 2009). Nevertheless, we did observe a negative correlation between the distance run after extinction training sessions 1 and 2 and freezing during the extinction memory tests on Days 2 and 3, as well as a significant improvement in contextual fear extinction recall a week later. These observations suggest that exercise can enhance the consolidation of contextual fear extinction memory, even if the effect was not large enough to be significantly different from locked controls during the initial memory tests. That exercise enhances recall of contextual fear extinction memory a week after the third fear extinction training session is especially interesting, as fear expression at long-term timepoints can be influenced by a number of factors in addition to the strength of the fear extinction memory, including generalization of the original fear memory (Wiltgen and Silva 2007), and the spontaneous recovery of fear (Bouton 1993). Thus, our data suggest that exercise during consolidation of contextual fear extinction may render fear extinction memory resistant to disruptive effects that tend to increase conditioned fear responding over time, even in the absence of improving short-term extinction memory, per se. This effect of exercise may be especially relevant to the longterm efficacy of extinction-based exposure therapy.

Chronic wheel running begun after contextual fear conditioning has been reported to reduce conditioned fear responding, even in the absence of fear extinction (Akers et al. 2014; Ishikawa et al. 2016). It was therefore important to determine whether the reduction in freezing observed on Day 10 in rats that ran after contextual fear extinction was dependent on wheel running being contingent with the consolidation of contextual fear extinction. Mobile rats not exposed to fear extinction, but that ran an equivalent time and distance to Mobile rats exposed to fear extinction, displayed freezing behavior equal to Locked rats not exposed to fear extinction (Fig. 3E), indicating that brief exercise sessions did not themselves alter the later expression of conditioned freezing. The reduction in freezing displayed by the Mobile rats on Day 10 is therefore dependent on exercise being contingent with the consolidation of contextual fear extinction.

We have previously reported that wheel running during the acquisition of auditory fear extinction reduces freezing to the CS in a novel context $1 \mathrm{wk}$ later (Mika et al. 2015). The design that was used, however, rendered fear extinction memory indistinguishable from renewal and spontaneous recovery. Experiment 2 thus investigated whether exercise during the consolidation of auditory fear extinction could both enhance fear extinction memory and reduce fear renewal. We found that exercise during the consolidation phase of auditory fear extinction both enhances fear extinction memory and blocks fear renewal one day following fear extinction. Rats that ran in the absence of extinction were excluded from this experiment because Experiment 1 revealed that brief running bouts in the absence of fear extinction learning have no effect on freezing (Fig. 4).

Interestingly, running distance during the wheel familiarization period prior to conditioning was negatively correlated to freezing during the acquisition of auditory conditioned fear (Fig. 6A). Consistent with this observation, distance run during the wheel familiarization period was also negatively correlated to the strength of the fear conditioning memory assessed by freezing during the first four trials of the first fear extinction training session (Fig. 
6B). While short-term exercise has profound effects on the hippocampus (Neeper et al. 1995, 1996; Molteni et al. 2002), a structure important for contextual fear conditioning (Rudy et al. 2002; Matus-Amat et al. 2004; Chang and Liang 2016), less is known regarding exercise effects on the amygdala, a region critical for the CS-US association formed during auditory fear conditioning (Huff and Rudy 2004; Bergstrom 2016). Moreover, the effects of exercise on auditory fear conditioning are not as well characterized as contextual fear conditioning (Baruch et al. 2004; Falls et al. 2010). To our knowledge, no prior research has investigated effects of only a few days of wheel running on auditory fear conditioning. Investigation of this question is warranted given the current results.

Rats that ran after the first day of auditory fear extinction displayed significantly less fear during reexposure to the auditory CS the following day. This is the first time, to our knowledge, that brief exercise has been reported to improve the consolidation of auditory fear extinction. Interestingly, the effect of exercise observed on extinction training Day 2 was not observed again the next day in the same context. Mobile rats did not freeze any less than Locked rats when reexposed to the $\mathrm{CS}$ in the extinction Context $\mathrm{B}$ (Same) during the fear renewal test on Day 3. This could be because all rats had, by this time, been exposed to two prior fear extinction training sessions, thus enabling Locked rats ample opportunity to learn fear extinction in Context $\mathrm{B}$ and reducing the difference between Locked and Mobile groups. Nevertheless, the fear extinction memory strengthened by exercise was resistant to renewal. When reexposed to the CS in an environment different from the extinction context, fear renewed in the rats placed into locked, but not mobile, wheels after extinction (Fig. 4D).

It is difficult to determine whether post-extinction exercise strengthens fear extinction memory consolidation or enables protection against memory disrupting effects. Conditioned freezing measured $24 \mathrm{~h}$ following fear extinction is commonly used as an index of fear extinction memory (Bukalo et al. 2015; Do-Monte et al. 2015), despite the possibility that spontaneous recovery could influence levels of freezing during the test. Nevertheless, the biggest effects of exercise were noted during long-term memory timepoints (Fig. 3E) or when fear renewal was promoted by reexposing rats to the extinguished CS in a new context (Fig. 4D). It is therefore possible that exercise both enhances fear extinction memory and renders the memory resistant to relapse phenomena. Future work will be required to determine whether similar mechanisms underlie these processes.

The mechanisms by which brief exercise could enhance fear extinction are unknown, but could involve several factors sensitive to brief exercise sessions, including increases in glucocorticoids, endocannabinoids, glutamatergic, noradrenergic and/or dopaminergic signaling. Indeed, acute increases in each of these factors can enhance fear extinction (for review, see Fitzgerald et al. 2014; Myskiw et al. 2014; Singewald et al. 2015), although in some cases the effects on fear relapse is not well established. The prefrontal cortex (mPFC), particularly the infralimbic region, is well known to be involved in fear extinction learning and memory (Do-Monte et al. 2015; Giustino and Maren 2015), and it is possible that exercise facilitates prefrontal mechanisms underlying extinction. Plasticity factors such as BDNF (Neeper et al. 1995) and mammalian target of rapamycin (Lloyd et al. 2017) are increased in the mPFC following at least a few days of wheel running, although whether a few hours of wheel running is enough to up-regulate plasticity factors in the mPFC is unknown. If exercise enhances fear extinction through mPFC mechanisms, one might expect that the infralimbic region of the mPFC would be more active during recall of fear extinction in exercising rats, as the infralimbic region is involved in fear extinction recall (Thompson et al. 2010; Chang and Maren 2011) and has been reported to express high lev- els of immediate early genes in rats with strong fear extinction memory (Knapska and Maren 2009). Using cfos mRNA as a marker of neural activation, Mika et al. (2015) found no evidence of potentiated neural activity in the infralimbic region during recall of relapse-resistant fear extinction memory in rats that exercised during fear extinction acquisition, compared with locked-wheel controls. However, enhanced fear extinction memory in rats that exercised during fear extinction acquisition was associated with a reduction in cfos mRNA in the prelimbic cortex, indicating that exercise could reduce the drive for fear initiated by the prelimbic region (Sierra-Mercado et al. 2011).

Mika et al. (2015) observed that the recall of relapse-resistant fear extinction in rats that ran during fear extinction acquisition was associated with potentiated activity of direct-pathway neurons in the striatum. This activity was above that which would be expected by locomotor activity or fear memory recall, suggesting that it was the recall of the fear extinction memory and not the reduction in freezing or fear response itself that was driving activation of striatal direct-pathway neurons. These data suggest that striatal direct-pathway neurons could be involved in the mechanisms by which brief exercise facilities fear extinction learning and reduces relapse. Although striatal direct-pathway neurons are typically considered in the context of locomotor activity, recent technical advances have revealed roles for these neurons in emotional behavior (Kravitz and Kreitzer 2012; Lenz and Lobo 2013). Further research is required to determine how these neurons could interact with other exercise signals and the canonical fear circuitry.

Because exercise had a more robust effect on auditory fear extinction compared with contextual fear extinction, we used auditory fear extinction to determine the effects of brief exercise on fear extinction and relapse in females. Consistent with the literature (Kandasamy et al. 2016; Venezia et al. 2016), female rats ran significantly more than male rats during both the familiarization and post-extinction phases (Fig. 2). Despite this vigorous wheel running, exercise neither enhanced the consolidation of auditory fear extinction nor prevented fear renewal in females. These data suggest that exercise might be a more useful strategy for augmentation of exposure therapy in males than in females.

It is well established that fear extinction learning and memory is dependent on the phase of the estrus/menstrual cycle in which female rats and humans initially learn extinction (Milad et al. 2009; Daviu et al. 2014). Consistent with these prior data, we observed that female rats that initially learned fear extinction in proestrus and estrus, phases of the estrus cycle during which levels of estradiol are highest, were protected against fear renewal (Fig. 5D). Relatively high levels of estradiol during proestrus and estrus phases could have contributed to this effect. Indeed, women with naturally low or experimentally reduced estrogen have impaired fear extinction (Zeidan et al. 2011; Graham and Milad 2013), and memory deficits present when rats learn fear extinction during phases of low estradiol can be prevented by preextinction estrogen receptor agonist, or rescued by post-extinction estradiol (Chang et al. 2009; Zeidan et al. 2011). Activation of estrogen receptor $B$ in the hippocampus $24 \mathrm{~h}$ prior to passive avoidance learning can increase the generalization of the memory of the context in which passive avoidance was learned to a neutral context (Lynch et al. 2014, 2016). It is possible that high estrogen levels during fear extinction learning could similarly promote later generalization of the extinction memory, therefore, reducing the contextual dependency of fear extinction. Given that no effects of exercise were observed in females regardless of estrous phase in which females were tested, it is likely that organizational effects of sex hormones underlie the observed sex differences, rather than activational effects mediated by the presence of sex hormones during adulthood. Future studies should further investigate how organizational and 
activational effects of female sex hormones modulate the impact of exercise on fear extinction learning and memory.

Collectively, the current data suggest that brief exercise sessions could be a useful strategy to augment treatment for anxietyand trauma-related disorders to help prevent relapse. This set of experiments further emphasizes the importance of investigating manipulations in females in addition to males, as we found that exercise differentially impacts auditory fear extinction learning and memory in male and female rats. These experiments expand our knowledge of factors able to modulate fear extinction learning and memory and provide building blocks upon which to further characterize the mechanisms by which exercise modulates fear extinction.

\section{Materials and Methods}

\section{Subjects}

Adult, male $(N=71, P \sim 54$ on date of arrival) or female $(N=40, P \sim$ 54 on date of arrival) Long-Evans rats were used for all experiments. Animals were pair-housed in ventilated rat cages $(45 \mathrm{~W} \times 25.2 \mathrm{D} \times$ $14.7 \mathrm{H} \mathrm{cm}$ ) with ad libitum access to food (standard Rat Chow) and water. The housing room was kept on a 12-h light-dark cycle with lights on from 0700 to 1900 and temperature was maintained at $25^{\circ} \mathrm{C}$. All procedures took place in the University of Colorado Denver Auraria campus animal facility accredited by the Association for Assessment and Accreditation of Laboratory Animal Care. Animals were allowed 1 wk to acclimate to their housing conditions before start of experimental manipulations. All rats were gently handled once daily during the last $4 \mathrm{~d}$ of this acclimation week. Care was taken to minimize pain and all protocols were approved by the University of Colorado Denver Institutional Animal Care and Use Committee.

\section{Estrus cycle monitoring}

After $1 \mathrm{wk}$ of acclimation to the vivarium, vaginal lavages were conducted every $24 \mathrm{~h}$ for five consecutive days in order to establish cycle and habituate rats to lavage. Briefly, a sterile, blunt-tip eyedropper was used to flush the vagina with $\sim 0.5 \mathrm{~mL}$ sterile filtered $0.2 \%$ PBS-Brij solution (Brij 35 Solution 30\%; Sigma-Aldrich, B4184) using the ventral method (Becker et al. 2005) to obtain vaginal epithelial cells. The fluid collected from lavages was transferred to a microscope slide and tissue was analyzed under bright-field at $400 \times$ (Olympus BX53). A single lavage was again collected $\sim 6 \mathrm{~h}$ prior to fear extinction learning, immediately following the fear renewal test, and immediately following the long-term extinction memory test to confirm phase of estrus cycle on these days. Estrus cycle phase was determined by the morphology of the cells collected during vaginal lavages as previously described (Cora et al. 2015). Briefly, proestrus consists of small, round, often clumped mononucleated cells of relatively the same size (Fig. 5F), the estrus phase is predominated by anucleated keratinized epithelial cells (Fig. 5G), metestrus consists of anucleated keratinized epithelial cells interspersed with leukocytes (Fig. 5H), and diestrus is predominated by leukocytes and nucleated epithelial cells with a decrease in anucleated keratinized epithelial cells (Fig. 5I).

\section{Wheel running}

At the start of all experiments, rats were placed into preassigned running wheels ( $1.1 \mathrm{~m}$ circumference; Lafayette Instruments) for the duration of the dark (active) cycle for four consecutive nights. On alternating nights, the wheels were rendered immobile so that, in total, rats had two nights of voluntary running in mobile running wheels and two nights in immobile (locked) running wheels. The purpose of this familiarization procedure was twofold: (1) to ensure that both the mobile and locked-wheel environments were equally familiar and (2) to increase running behavior after extinction, as in our experience rats lacking prior experience with a running wheel run minimally. All wheel running activity was re- corded with Activity Wheel Monitor software (Lafayette Instruments).

\section{Fear conditioning}

Between 0800 and 1100, rats were placed into custom, rectangular conditioning chambers $\left(20^{\prime \prime} \mathrm{W} \times 10^{\prime \prime} \mathrm{D} \times 12^{\prime \prime} \mathrm{H}\right.$; Context A) with a shock grid floor (Coulbourn Instruments) housed inside individual sound-attenuating cabinets. Rats were transported to Context A in their home cages. A fan located near the floor of the cabinets provided ventilation and background noise and bright white lights illuminated the chambers. For contextual fear conditioning (Experiment 1), rats were allowed $5 \mathrm{~min}$ to explore the context, after which three footshock US (1 sec, $0.8 \mathrm{~mA}$ ) were delivered with a 1-min ITI. For auditory fear conditioning (Experiments 2 and 3), rats were allowed to explore the context for $3 \mathrm{~min}$, followed by four exposures to an auditory CS (10 sec, $80 \mathrm{~dB}, 2 \mathrm{kH})$, each coterminating with a 1-sec, 0.08 -mA footshock US delivered on a $1 \mathrm{~min}$ ITI. Auditory stimuli and footshocks were delivered through Coulbourn tone generators and shock scramblers controlled via Noldus EthoVision XT software through a custom interface. All rats remained in the conditioning chamber for $1 \mathrm{~min}$ after the last shock before being transported back to their home cages. Chambers were cleaned with water between rats. Freezing behavior, an innate fear response, was defined as the absence of all movement except that required for respiration (Fanselow 1980) and was used as the measure of fear in all behavior tests.

\section{Fear extinction}

Each fear extinction training session took place near the start of the active (dark) cycle, to maximize running behavior of rats in the Mobile group (Greenwood et al. 2011). Rats exposed to contextual fear extinction (Experiment 1) were placed into context A for 15 min in the absence of the shock US. All transport, lighting, and cleaning conditions were identical to fear conditioning. Rats exposed to auditory fear extinction (Experiments 2 and 3) were placed into a novel Context $\mathrm{B}$ that was either a custom Plexiglas rectangular chamber $\left(15^{\prime \prime} \mathrm{W} \times 15^{\prime \prime} \mathrm{D} \times 20^{\prime \prime} \mathrm{H}\right)$ with a textured floor or a custom Plexiglas triangular chamber $\left(15^{\prime \prime}\right.$ sides $\left.\times 20^{\prime \prime} \mathrm{H}\right)$ with a smooth floor. Rectangular and triangular Context B chambers were counterbalanced so half the rats were exposed to fear extinction training in the rectangular chambers and the other half in the triangular chambers. Context B was housed in the same sound-attenuating cabinets used for conditioning, but all other contextual features and discrete cues differed between contexts. Rats were transported to the sound-attenuating chambers, which included vanilla scent, in their assigned Context B custom Plexiglas chamber. The fan within the chamber was turned off and the room was dimly lit by a lamp outside of the soundattenuating chambers. Context B was cleaned with $10 \%$ ethanol between rats. After a 3-min exploration period, the auditory CS was administered 30 times (1-min ITI) in the absence of the footshock US. Similar auditory extinction parameters have been used previously in Long-Evans rats (Maren 2014).

\section{Post-extinction wheel running}

Immediately following contextual or auditory fear extinction, rats were transferred to their familiar running wheels that were either rendered immobile (Locked) or freely mobile (Mobile). Rats were assigned to Locked or Mobile conditions based on freezing levels during fear conditioning, such that freezing levels during conditioning were balanced between wheel assignments. Rats were returned to their home cages following $2 \mathrm{~h}$ of exposure to the locked or mobile wheels. Rats in the "No Extinction" group were placed in their assigned Locked or Mobile wheels for $2 \mathrm{~h}$ per night, but were not exposed to fear extinction.

\section{Fear renewal test}

Between 0800 and 1100, rats exposed to auditory fear conditioning and extinction were reexposed to the auditory CS in either the same context used for extinction training (Context B; Same) or a 
novel Context C (Different). Rats were assigned to Same or Different contexts based on freezing levels during fear extinction, such that freezing levels during extinction were balanced between groups. Rats assigned to the Different group were transported to Context $\mathrm{C}$ in a novel inner Plexiglass chamber, so that rats extinguished in the square Plexiglass chamber were now placed into the triangle, and vice versa. Context $\mathrm{C}$ consisted of a raspberry scent, red box lights, a fan near the top of the behavior cabinets was turned on, and chambers were cleaned with $1 \%$ acetic acid between tests. After a 3-min exploration period, the auditory CS was presented four times (1-min ITI) in the absence of the footshock US. Because fear renewal is the return of fear in contexts different from where fear extinction was learned (Bouton and Ricker 1994), the difference in freezing between the Same and Different contexts was considered fear renewal.

\section{Procedures}

\section{Experiment 1: effects of acute exercise on extinction of contextual fear conditioning}

A timeline for the experiment is shown in Figure 1A. Prior to fear conditioning, rats ( $N=32$ males) were exposed to the running wheel familiarization procedure, so each rat spent two active cycles in mobile, voluntary running wheels alternating with two active cycles in the same locked running wheel. Three days following the second running opportunity, rats underwent contextual fear conditioning in Context A. During the following three evenings, immediately prior to the dark (active) cycle, rats were reexposed to Context A for 15 min in the absence of shock, in order to extinguish contextual fear. Each of the three, 15 min extinction training sessions was immediately followed by $2 \mathrm{~h}$ in familiar Locked $(n=$ $11)$ or Mobile $(n=11)$ running wheels, so that rats in the Mobile group ran in wheels during the consolidation phase of contextual fear extinction. Rats were again exposed to Context A $1 \mathrm{wk}$ following the third contextual fear extinction training session in order to assess the effects of post-extinction wheel running on long-term extinction memory/spontaneous recovery of fear. An additional cohort of rats were conditioned and placed into their assigned mobile or locked running wheels at the same time as the other rats, but were not exposed to fear extinction training. This subset of Locked $(n=5)$ or Mobile $(n=5)$ rats was placed into Context A on the day of the long-term extinction memory/spontaneous recovery test to assess potential effects of running in the absence of fear extinction training on subsequent freezing behavior.

\section{Experiment 2: effects of acute exercise on extinction and renewal of auditory conditioned fear in males}

A timeline for the experiment is shown in Figure 1B. Three days following the second familiarization running opportunity, rats $(N=$ 39 males) underwent auditory fear conditioning in Context A. The following two evenings, immediately prior to the dark (active) cycle, rats were exposed to auditory fear extinction training in Context B immediately followed by placement for $2 \mathrm{~h}$ into their familiar Locked $(n=20)$ or Mobile $(n=19)$ running wheels, so that rats assigned to the Mobile condition had the opportunity to run during the fear extinction consolidation period. The morning after the second fear extinction training session, rats were again exposed to the CS either in the extinction Context B (Locked Same $n=10$; Mobile Same $n=10$ ) or in a novel Context C (Locked Different $n$ $=10$; Mobile Different $n=9$ ) to assess fear renewal.

\section{Experiment 3: effects of acute exercise on extinction and renewal of auditory fear conditioning in females}

A timeline for the experiment is shown in Figure 1C. Experiment 2 was repeated except cycling females ( $n=40$ females) were used instead of males. Since males and females have been reported to similarly acquire auditory fear conditioning (Maren et al. 1994), female rats in experiment 3 were administered the same number of CS-US pairings during conditioning as male rats in experiment 2. Pilot studies revealed that females displayed less freezing behavior during fear extinction memory tests than males. Therefore, to help avoid floor effects on freezing, females were exposed to 20 CS presentations during fear extinction training. A long-term fear extinction memory/spontaneous recovery test was added $1 \mathrm{wk}$ after the fear renewal test.

All behavioral tests were recorded with overhead cameras and freezing was scored both by multiple experimenters blind to the experimental conditions of the animals and by automated behavioral analyses software (Noldus Ethovision XT) during both the CS and the ITIs. Because regularly scheduled ITIs can become part of the CS, and analyses indicated a lack of differential effects of exercise on freezing during ITIs and CS, freezing during each CS and subsequent ITI were combined and expressed as freezing during a trial, as in prior work (Fitzgerald et al. 2015; Goode et al. 2015; Mika et al. 2015).

\section{Statistical analysis}

Running distances were calculated using the Lafayette Instruments Activity Wheel Monitor data management add-on for Microsoft Excel, then total running distances were analyzed using ANOVA. Percent time spent freezing was calculated by averaging freezing data from individual experimenters blind to treatment condition of the animals with immobility times obtained from Noldus Ethovision XT. Preshock freezing for each test was averaged and group differences were analyzed with ANOVA. Average freezing across minutes during conditioning (Experiment 1 ) or across trials during conditioning and extinction (Experiments 2 and 3) were analyzed using repeated-measures ANOVA. Freezing scores within each extinction session in Experiment 1 were averaged and group differences compared using ANOVA. For renewal, freezing across trials was averaged and compared using two-way ANOVA with Exercise and Context conditions as factors. For long-term memory/spontaneous recovery tests, overall group means were analyzed using ANOVA. Estrus phase was added as a factor in Experiment 3; therefore, two-way repeated-measures ANOVAs (Exercise $\times$ Estrus Phase) were used to analyze freezing during extinction days, and a three-way ANOVA (Exercise $\times$ Context $\times$ Estrus Phase) was used to compare group means during the renewal test. Simple regressions were run to determine whether running distance during the running familiarization phase or after fear extinction predicted freezing levels during subsequent behavioral tests. Fisher's least significant differences post hoc analyses were performed when appropriate. Group differences were considered different when $P \leq 0.05$.

\section{References}

Akers KG, Martinez-Canabal A, Restivo L, Yiu AP, De Cristofaro A Hsiang HL, Wheeler AL, Guskjolen A, Niibori Y, Shoji H, et al. 2014. Hippocampal neurogenesis regulates forgetting during adulthood and infancy. Science 344: 598-602.

Baruch DE, Swain RA, Helmstetter FJ. 2004. Effects of exercise on Pavlovian fear conditioning. Behav Neurosci 118: 1123-1127.

Becker JB, Arnold AP, Berkley KJ, Blaustein JD, Eckel LA, Hampson E Herman JP, Marts S, Sadee W, Steiner M, et al. 2005. Strategies and methods for research on sex differences in brain and behavior. Endocrinology 146: 1650-1673.

Bergstrom HC. 2016. The neurocircuitry of remote cued fear memory. Neurosci Biobehav Rev 71: 409-417.

Boschen MJ, Neumann DL, Waters AM. 2009. Relapse of successfully treated anxiety and fear: theoretical issues and recommendations for clinical practice. Aust N Z J Psychiatry 43: 89-100.

Bouton ME. 1988. Context and ambiguity in the extinction of emotional learning: implications for exposure therapy. Behav Res Ther 26: 137-149.

Bouton ME. 1993. Context, time, and memory retrieval in the interference paradigms of Pavlovian learning. Psychol Bull 114: 80-99.

Bouton ME, Ricker ST. 1994. Renewal of extinguished responding in a 2nd context. Anim Learn Behav 22: 317-324.

Breslau N, Davis GC, Andreski P, Peterson EL, Schultz LR. 1997. Sex differences in posttraumatic stress disorder. Arch Gen Psychiatry 54: 1044-1048.

Bukalo O, Pinard CR, Silverstein S, Brehm C, Hartley ND, Whittle N, Colacicco G, Busch E, Patel S, Singewald N, et al. 2015. Prefrontal inputs 
to the amygdala instruct fear extinction memory formation. Sci Adv $\mathbf{1}$ : e1500251.

Burghardt PR, Pasumarthi RK, Wilson MA, Fadel J. 2006. Alterations in fear conditioning and amygdalar activation following chronic wheel running in rats. Pharmacol Biochem Behav 84: 306-312.

Cassilhas RC, Tufik S, de Mello MT. 2015. Physical exercise, neuroplasticity, spatial learning and memory. Cell Mol Life Sci 73: 975-983.

Chang SD, Liang KC. 2016. The hippocampus integrates context and shock into a configural memory in contextual fear conditioning. Hippocampus 27: 145-155.

Chang CH, Maren S. 2011. Medial prefrontal cortex activation facilitates reextinction of fear in rats. Learn Mem 18: 221-225.

Chang YJ, Yang CH, Liang YC, Yeh CM, Huang CC, Hsu KS. 2009. Estrogen modulates sexually dimorphic contextual fear extinction in rats through estrogen receptor $\beta$. Hippocampus 19: 1142-1150.

Cora MC, Kooistra L, Travlos G. 2015. Vaginal cytology of the laboratory rat and mouse: review and criteria for the staging of the estrous cycle using stained vaginal smears. Toxicol Pathol 43: 776-793.

Cotman CW, Berchtold NC. 2002. Exercise: a behavioral intervention to enhance brain health and plasticity. Trends Neurosci 25: 295-301.

Daviu N, Andero R, Armario A, Nadal R. 2014. Sex differences in the behavioural and hypothalamic-pituitary-adrenal response to contextual fear conditioning in rats. Horm Behav 66: 713-723.

Dishman R. 1982. Compliance/adherence in health-related exericse. Health Psychol 1: 30.

Do-Monte FH, Manzano-Nieves G, Quiñones-Laracuente K, Ramos-Medina L, Quirk GJ. 2015. Revisiting the role of infralimbic cortex in fear extinction with optogenetics. J Neurosci 35: 3607-3615.

Dubreucq S, Marsicano G, Chaouloff F. 2015. Duration- and environment-dependent effects of repeated voluntary exercise on anxiety and cued fear in mice. Behav Brain Res 282: 1-5.

Elzinga BM, Bremner JD. 2002. Are the neural substrates of memory the final common pathway in posttraumatic stress disorder (PTSD)? J Affect Disord 70: $1-17$.

Falls WA, Fox JH, MacAulay CM. 2010. Voluntary exercise improves both learning and consolidation of cued conditioned fear in C57 mice. Behav Brain Res 207: 321-331.

Fanselow MS. 1980. Conditioned and unconditional components of post-shock freezing. Pavlov J Biol Sci 15: 177-182.

Fitzgerald PJ, Seemann JR, Maren S. 2014. Can fear extinction be enhanced? A review of pharmacological and behavioral findings. Brain Res Bull 105: $46-60$.

Fitzgerald PJ, Giustino TF, Seemann JR, Maren S. 2015. Noradrenergic blockade stabilizes prefrontal activity and enables fear extinction under stress. Proc Natl Acad Sci 112: E3729-E3737.

Giustino TF, Maren S. 2015. The role of the medial prefrontal cortex in the conditioning and extinction of fear. Front Behav Neurosci 9: 298

Goode TD, Kim JJ, Maren S. 2015. Reversible inactivation of the bed nucleus of the stria terminalis prevents reinstatement but not renewal of extinguished fear $(1,2,3)$. eNeuro 2. doi: 10.1523/ENEURO.0037-15.2015

Graham BM, Milad MR. 2013. Blockade of estrogen by hormonal contraceptives impairs fear extinction in female rats and women. Biol Psychiatry 73: 371-378.

Greenwood BN, Strong PV, Foley TE, Fleshner M. 2009. A behavioral analysis of the impact of voluntary physical activity on hippocampus-dependent contextual conditioning. Hippocampus 19: 988-1001.

Greenwood BN, Foley TE, Le TV, Strong PV, Loughridge AB, Day HE, Fleshner M. 2011. Long-term voluntary wheel running is rewarding and produces plasticity in the mesolimbic reward pathway. Behav Brain Res 217: $354-362$.

Hillman CH, Snook EM, Jerome GJ. 2003. Acute cardiovascular exercise and executive control function. Int J Psychophysiol 48: 307-314.

Hillman CH, Pontifex MB, Castelli DM, Khan NA, Raine LB, Scudder MR, Drollette ES, Moore RD, Wu CT, Kamijo K. 2014. Effects of the FITKids randomized controlled trial on executive control and brain function. Pediatrics 134: e1063-e1071.

Hogg L, Garrod R, Thornton H, McDonnell L, Bellas H, White P. 2012. Effectiveness, attendance, and completion of an integrated, system-wide pulmonary rehabilitation service for COPD: prospective observational study. COPD 9: 546-554.

Huff NC, Rudy JW. 2004. The amygdala modulates hippocampus-dependent context memory formation and stores cue-shock associations. Behav Neurosci 118: 53-62.

Ishikawa R, Fukushima H, Frankland PW, Kida S. 2016. Hippocampal neurogenesis enhancers promote forgetting of remote fear memory after hippocampal reactivation by retrieval. Elife 5: e17464.

Kandasamy R, Calsbeek JJ, Morgan MM. 2016. Home cage wheel running is an objective and clinically relevant method to assess inflammatory pain in male and female rats. J Neurosci Methods 263: 115-122.
Knapska E, Maren S. 2009. Reciprocal patterns of c-Fos expression in the medial prefrontal cortex and amygdala after extinction and renewal of conditioned fear. Learn Mem 16: 486-493.

Kohman RA, Clark PJ, Deyoung EK, Bhattacharya TK, Venghaus CE, Rhodes JS. 2012. Voluntary wheel running enhances contextual but not trace fear conditioning. Behav Brain Res 226: 1-7.

Kravitz AV, Kreitzer AC. 2012. Striatal mechanisms underlying movement, reinforcement, and punishment. Physiology (Bethesda) 27: 167-177.

Lebron-Milad K, Milad MR. 2012. Sex differences, gonadal hormones and the fear extinction network: implications for anxiety disorders. Biol Mood Anxiety Disord 2: 3.

Lenz JD, Lobo MK. 2013. Optogenetic insights into striatal function and behavior. Behav Brain Res 255: 44-54.

Lloyd BA, Hake HS, Ishiwata T, Farmer CE, Loetz EC, Fleshner M, Bland ST, Greenwood BN. 2017. Exercise increases mTOR signaling in brain regions involved in cognition and emotional behavior. Behav Brain Res 323: $56-67$.

Lynch JF III, Dejanovic D, Winiecki P, Mulvany J, Ortiz S, Riccio DC, Jasnow AM. 2014. Activation of ER $\beta$ modulates fear generalization through an effect on memory retrieval. Horm Behav 66: 421-429.

Lynch JF III, Winiecki P, Vanderhoof T, Riccio DC, Jasnow AM. 2016. Hippocampal cytosolic estrogen receptors regulate fear generalization in females. Neurobiol Learn Mem 130: 83-92.

Maren S. 2014. Fear of the unexpected: hippocampus mediates novelty-induced return of extinguished fear in rats. Neurobiol Learn Mem 108: 88-95.

Maren S, De Oca B, Fanselow MS. 1994. Sex differences in hippocampal long-term potentiation (LTP) and Pavlovian fear conditioning in rats: positive correlation between LTP and contextual learning. Brain Res 661: $25-34$.

Matus-Amat P, Higgins EA, Barrientos RM, Rudy JW. 2004. The role of the dorsal hippocampus in the acquisition and retrieval of context memory representations. J Neurosci 24: 2431-2439.

McLean CP, Asnaani A, Litz BT, Hofmann SG. 2011. Gender differences in anxiety disorders: prevalence, course of illness, comorbidity and burden of illness. J Psychiatr Res 45: 1027-1035.

Mika A, Bouchet CA, Bunker P, Hellwinkel JE, Spence KG, Day HE, Campeau S, Fleshner M, Greenwood BN. 2015. Voluntary exercise during extinction of auditory fear conditioning reduces the relapse of fear associated with potentiated activity of striatal direct pathway neurons. Neurobiol Learn Mem 125: 224-235.

Milad MR, Igoe SA, Lebron-Milad K, Novales JE. 2009. Estrous cycle phase and gonadal hormones influence conditioned fear extinction. Neuroscience 164: 887-895.

Molteni R, Ying Z, Gómez-Pinilla F. 2002. Differential effects of acute and chronic exercise on plasticity-related genes in the rat hippocampus revealed by microarray. Eur J Neurosci 16: 1107-1116.

Myskiw JC, Izquierdo I, Furini CR. 2014. Modulation of the extinction of fear learning. Brain Res Bull 105: 61-69.

Neeper SA, Gómez-Pinilla F, Choi J, Cotman C. 1995. Exercise and brain neurotrophins. Nature 373: 109.

Neeper SA, Gómez-Pinilla F, Choi J, Cotman CW. 1996. Physical activity increases mRNA for brain-derived neurotrophic factor and nerve growth factor in rat brain. Brain Res 726: 49-56.

Neumann DL, Kitlertsirivatana E. 2010. Exposure to a novel context after extinction causes a renewal of extinguished conditioned responses: implications for the treatment of fear. Behav Res Ther 48: 565-570.

Pavlov IP. 1927. Conditioned reflex: an investigation of the physiological activity of the cerebral cortex. Oxford University Press, Oxford, England.

Ponnusamy R, Zhuravka I, Poulos AM, Shobe J, Merjanian M, Huang J, Wolvek D, O'Neill PK, Fanselow MS. 2016. Retrieval and reconsolidation accounts of fear extinction. Front Behav Neurosci 10: 89.

Powers MB, Medina JL, Burns S, Kauffman BY, Monfils M, Asmundson GJ, Diamond A, McIntyre C, Smits JA. 2015. Exercise augmentation of exposure therapy for PTSD: rationale and pilot efficacy data. Cogn Behav Ther 44: 314-327.

Prakash RS, Voss MW, Erickson KI, Kramer AF. 2015. Physical activity and cognitive vitality. Annu Rev Psychol 66: 769-797.

Rescorla RA, Heth CD. 1975. Reinstatement of fear to an extinguished conditioned stimulus. J Exp Psychol Anim Behav Process 1: 88-96.

Rudy JW, Barrientos RM, O'Reilly RC. 2002. Hippocampal formation supports conditioning to memory of a context. Behav Neurosci 116: 530-538.

Sierra-Mercado D, Padilla-Coreano N, Quirk GJ. 2011. Dissociable roles of prelimbic and infralimbic cortices, ventral hippocampus, and basolateral amygdala in the expression and extinction of conditioned fear. Neuropsychopharmacology 36: 529-538.

Siette J, Reichelt AC, Westbrook RF. 2014. A bout of voluntary running enhances context conditioned fear, its extinction, and its reconsolidation. Learn Mem 21: 73-81. 
Singewald N, Schmuckermair C, Whittle N, Holmes A, Ressler KJ. 2015. Pharmacology of cognitive enhancers for exposure-based therapy of fear, anxiety and trauma-related disorders. Pharmacol Ther 149: 150-190.

Thompson BM, Baratta MV, Biedenkapp JC, Rudy JW, Watkins LR, Maier SF. 2010. Activation of the infralimbic cortex in a fear context enhances extinction learning. Learn Mem 17: 591-599.

Van Hoomissen JD, Holmes PV, Zellner AS, Poudevigne A, Dishman RK. 2004. Effects of $\beta$-adrenoreceptor blockade during chronic exercise on contextual fear conditioning and mRNA for galanin and brain-derived neurotrophic factor. Behav Neurosci 118: 1378-1390.

Van Roie E, Bautmans I, Coudyzer W, Boen F, Delecluse C. 2015. Low- and high-resistance exercise: long-term adherence and motivation among older adults. Gerontology 61: 551-560.

Venezia AC, Guth LM, Sapp RM, Spangenburg EE, Roth SM. 2016. Sex-dependent and independent effects of long-term voluntary wheel running on Bdnf mRNA and protein expression. Physiol Behav 156: $8-15$.

Wiltgen BJ, Silva AJ. 2007. Memory for context becomes less specific with time. Learn Mem 14: 313-317.

Zeidan MA, Igoe SA, Linnman C, Vitalo A, Levine JB, Klibanski A, Goldstein JM, Milad MR. 2011. Estradiol modulates medial prefrontal cortex and amygdala activity during fear extinction in women and female rats. Biol Psychiatry 70: 920-927.

Zuckoff A. 2012. "Why won't my patients do what's good for them?" Motivational interviewing and treatment adherence. Surg Obes Relat Dis 8: $514-521$.

Received February 2, 2017; accepted in revised form May 8, 2017. 


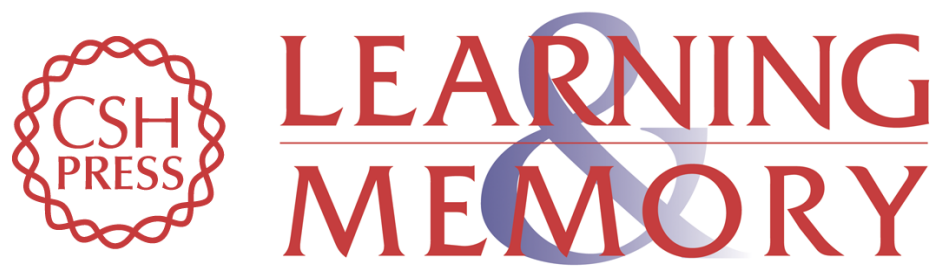

\section{Acute exercise enhances the consolidation of fear extinction memory and reduces conditioned fear relapse in a sex-dependent manner}

Courtney A. Bouchet, Brian A. Lloyd, Esteban C. Loetz, et al.

Learn. Mem. 2017, 24:

Access the most recent version at doi:10.1101/Im.045195.117

References This article cites 71 articles, 11 of which can be accessed free at: http://learnmem.cshlp.org/content/24/8/358.full.html\#ref-list-1

Creative This article is distributed exclusively by Cold Spring Harbor Laboratory Press for the Commons first 12 months after the full-issue publication date (see

License http://learnmem.cshlp.org/site/misc/terms.xhtml). After 12 months, it is available under a Creative Commons License (Attribution-NonCommercial 4.0 International), as described at http://creativecommons.org/licenses/by-nc/4.0/.

Email Alerting Receive free email alerts when new articles cite this article - sign up in the box at the Service top right corner of the article or click here. 